\title{
Pendekatan Ekologi pada Rancangan Rumah Susun Sewa Adaptable bagi Pekerja Pabrik di Kawasan Sub-Urban Kabupaten Sidoarjo
}

\author{
Maulysa Prahastuti dan Ima Defiana \\ Departemen Arsitektur, Fakultas Teknik Sipil dan Perencanaan, Institut Teknologi Sepuluh Nopember (ITS) \\ e-mail: may_d@arch.its.ac.id
}

\begin{abstract}
Abstrak-Fenomena urban sprawl di Surabaya hadir akibat urbanisasi yang terus-menerus. Urbanisasi menyebabkan terjadinya ketidakseimbangan ketersediaan dan kebutuhan hunian. Hal tersebut menyebabkan harga hunian menjadi tinggi. Harga hunian yang tinggi tidak sesuai dengan pendapatan pekerja pabrik. Tekanan ekonomi pada pekerja pabrik menyebabkan mereka membuat lingkungan baru di pinggiran kota. Pinggiran kota identik dengan lingkungan yang kumuh dan akses yang sulit untuk menjangkaunya. Hal tersebut dapat dikatakan bahwa akses pekerja pabrik untuk mendapatkan hunian yang layak sangatlah minim. Oleh karena itu, diperlukan penyediaan hunian bagi pekerja pabrik berupa rumah susun. Banyaknya rumah susun yang tidak dapat menyesuaikan adanya perubahan kebutuhan ruang akan menyebabkan kekumuhan pada rumah susun. Salah satu cara menyelesaikan kekumuhan pada hunian pekerja pabrik adalah perancangan rumah susun yang adaptable (dapat menyesuaikan terhadap penghuni, lingkungan, dan objek). Perancangan adaptable dicapai dengan metode desain Adaptive Architecture. Selain itu, perancangan rumah susun juga menggunakan pendekatan ekologi.
\end{abstract}

Kata Kunci-Adaptable, Adaptive Architecture, Ekologi, Hunian, Urban Sprawl.

\section{PENDAHULUAN}

$\mathrm{S}$ EKTOR industri yang berkembang pesat di Surabaya, menyebabkan banyak masyarakat yang berpindah dari desa ke kota untuk mencari pekerjaan. Urbanisasi yang terus terjadi, menyebabkan terjadinya fenomena urban sprawl [1]. Fenomena urban sprawl di Surabaya memiliki Kota Surabaya sebagai kota intinya serta Kabupaten Gresik, Bangkalan, Mojokerto, Sidoarjo, dan Lamongan sebagai wilayah pinggirannya. Daerah pemekaran yang memiliki kepadatan penduduk paling tinggi adalah Kabupaten Sidoarjo.

Banyaknya penduduk di kawasan perkotaan menyebabkan terjadinya ketidakseimbangan ketersediaan dan kebutuhan hunian. Hal tersebut menyebabkan harga hunian menjadi tinggi. Harga hunian tinggi tidak sesuai dengan pendapatan pekerja pabrik yang sebatas Upah Minimum Regional. Hal tersebut menyebabkan pekerja pabrik memilih bertempat tinggal di pinggiran kota. Namun, pinggiran kota identik dengan lingkungan yang kumuh dan akses sulit untuk menjangkaunya. Oleh karena itu, diperlukan penyediaan hunian yang layak dan terjangkau bagi pekerja pabrik berupa rumah susun.

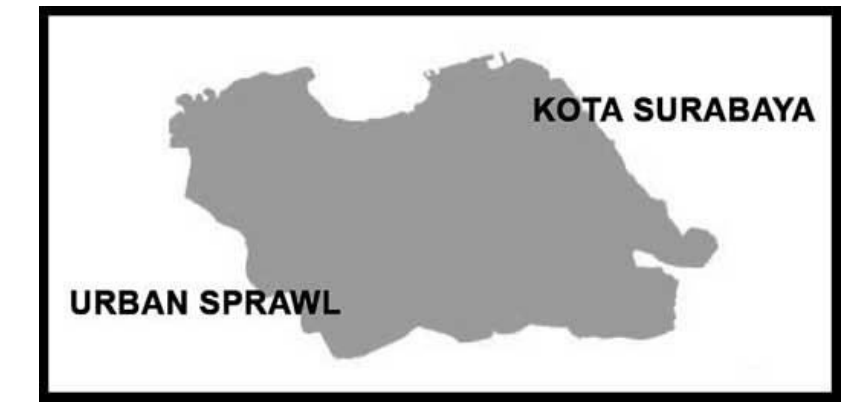

Gambar 1. Peta Surabaya.

Sumber: Google

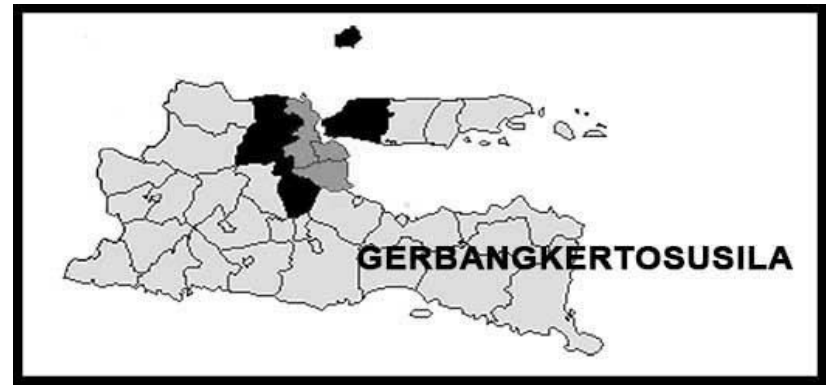

Gambar 2. Wilayah Urban Sprawl.

Sumber: Google

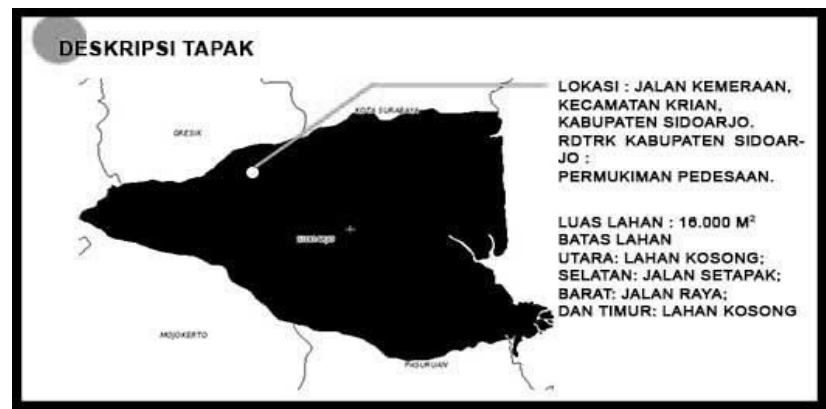

Gambar 3. Deskripsi Tapak.

Sumber: Google

Kekumuhan pada hunian pekerja pabrik dapat diselesaikan dengan berbagai cara, salah satunya dengan desain adaptable. Desain adaptable yang dimaksud adalah desain yang dapat menyesuaikan terhadap penghuni, lingkungan, dan objek. Selain itu, desain adaptable juga dapat mengakomodasi adanya perubahan dan penambahan ruang sesuai dengan kebutuhan penghuninya. 
Tabel 1.

Aktivitas Keluarga Pak Muhammad Soleh

\begin{tabular}{|c|c|c|c|}
\hline Hari & $\begin{array}{c}\text { Ayah } \\
\text { (Kerja di PT. } \\
\text { Kedawung Setia) }\end{array}$ & $\begin{array}{c}\text { Ibu } \\
\text { (Ibu Rumah } \\
\text { Tangga) }\end{array}$ & $\begin{array}{c}\text { Anak } \\
\text { (Sekolah) }\end{array}$ \\
\hline $\begin{array}{lll}\text { Hari } & \text { kerja } & \text { (Senin- } \\
\text { Sabtu) } & & \\
\end{array}$ & $\begin{array}{l}\text { - Bekerja shift } \\
\text { Shift } 1 \text { (06.30- } \\
14.30) \\
\text { Shift } 2 \text { (14.30- } \\
22.30) \\
\text { Shift } 3 \quad(22.30- \\
06.30) \\
\text { - Merawat cucu } \\
\text { - Beribadah ke } \\
\text { masjid } \\
\text { - Menonton TV } \\
\text { atau mende- } \\
\text { ngarkan radio } \\
\text { - Beristirahat }\end{array}$ & $\begin{array}{l}\cdot \text { Mencuci } \\
\cdot \text { Menjemur } \\
\cdot \text { Belanja } \\
\cdot \text { Memasak } \\
\cdot \text { Membersihkan } \\
\text { rumah } \\
\cdot \text { Merawat cucu } \\
\cdot \text { Berkumpul } \\
\text { dengan tetangga } \\
\cdot \text { Beristirahat }\end{array}$ & $\begin{array}{l}\text { - Sekolah } \\
(07.00-12.30) \\
\cdot \text { Belajar } \\
\cdot \text { Bermain } \\
\text { dengan teman } \\
\cdot \text { Merawat } \\
\text { keponakan } \\
\text { - Membantu } \\
\text { orang tua } \\
\text { - Beristirahat }\end{array}$ \\
\hline \begin{tabular}{|l} 
Hari libur (Minggu) \\
\end{tabular} & $\begin{array}{l}\text { - Berkumpul } \\
\text { dengan keluarga } \\
\text { - Bermain dengan } \\
\text { cucu } \\
\text { - Jalan-jalan } \\
\text { dengan cucu } \\
\text { - Beristirahat }\end{array}$ & $\begin{array}{l}\cdot \text { - Mencuci } \\
\cdot \text { Menjemur } \\
\cdot \text { Memasak } \\
\cdot \text { Membersihkan } \\
\text { rumah } \\
\cdot \text { Berkumpul } \\
\text { dengan } \\
\text { keluarga } \\
\text { - Jalan-jalan } \\
\text { dengan anak } \\
\text { - Berkumpul } \\
\text { dengan tetangga } \\
\text { - Beristirahat }\end{array}$ & $\begin{array}{l}\text { - Menonton TV } \\
\cdot \text { Bermain } \\
\text { dengan teman } \\
\text { - Jalan-jalan } \\
\text { dengan } \\
\text { keluarga } \\
\text { - Beristirahat }\end{array}$ \\
\hline
\end{tabular}

Selain menerapkan desain adaptable, rumah susun juga menerapkan pendekatan ekologi untuk menyelesaikan masalah kekumuhan. Penerapan pendekatan ekologi juga diharapkan agar rumah susun tidak banyak memberikan dampak buruk ke lingkungan. Selain itu, pendekatan ini diharapkan dapat mengurangi pembiayaan dan penggunaan energi pada rumah susun.

\section{METODE PERANCANGAN}

Metode yang digunakan dalam merancang rumah susun adaptable ini adalah Metode Arsiektur Adaptif [2]. Arsitektur Adaptif bersangkutan dengan bangunan yang dirancang untuk beradaptasi dengan lingkungan bangunan, penghuni bangunan, dan benda yang ada di dalamnya. Adapun beberapa tahapan dari metode ini, antara lain adalah:

\section{A. Human Intervention}

Intervensi dari manusia dilakukan untuk mengetahui siapa penghuni dari objek arsitektur. karakteristik dari pekerja pabrik, kebutuhan hunian dari pekerja pabrik. Intervensi manusia dibutuhkan untuk memicu adaptasi pada bangunan.

\section{B. Technical Data Source}

Data yang terekam meliputi data kegiatan penghuni (Tabel 1 dan 2), informasi lingkungan, dan informasi tentang objek. Informasi yang didapat dianalisa untuk menentukan elemen adaptasi apa yang akan digunakan.

\section{System and Processing}

Data yang terekam diolah melalui sistem jaringan sensor, atau sistem manajemen gedung. Pengolahan data berguna
Tabel 2.

Aktivitas Keluarga Ibu Atinah

\begin{tabular}{|c|c|c|c|}
\hline Hari & $\begin{array}{c}\text { Ayah } \\
\text { (Kerja di PT. } \\
\text { Platinum) }\end{array}$ & $\begin{array}{c}\text { Ibu } \\
\text { (Kerja di PT. } \\
\text { Platinum) }\end{array}$ & $\begin{array}{c}\text { Anak } \\
\text { (Sekolah) }\end{array}$ \\
\hline $\begin{array}{lll}\text { Hari kerja } & \text { (Senin- } \\
\text { Sabtu) } & & \\
\end{array}$ & $\begin{array}{l}\text { - Bekerja shift } \\
\text { Shift } \quad 1 \quad(07.30- \\
15.30) \\
\text { Shift } 2 \quad(15.30- \\
23.30) \\
\text { Shift } 3 \quad(23.30- \\
07.30) \\
\text { - Beristirahat } \\
\text { - Merawat anak } \\
\text { - Membantu istri }\end{array}$ & $\begin{array}{l}\text { - Bekerja shift } \\
\text { Shift } 1 \quad(07.30- \\
15.30) \\
\text { Shift } 2 \text { (15.30- } \\
23.30) \\
\text { Shift } 3 \quad(23.30- \\
07.30) \\
\text { - Mencuci } \\
\text {-Menjemur } \\
\text { - Belanja } \\
\text { - Memasak } \\
\text { • Membersihkan } \\
\text { rumah } \\
\text { - Merawat anak } \\
\text { - Beristirahat }\end{array}$ & $\begin{array}{l}\text { - Sekolah } \\
\text { (07.00-16.00) } \\
\text { - Dititipkan ke } \\
\text { tetangga } \\
\text { - Bermain } \\
\text { dengan } \\
\text { tetangga } \\
\text { - Beristirahat }\end{array}$ \\
\hline Hari libur (Minggu) & $\begin{array}{l}\text { - Merawat anak } \\
\text { - Membantu istri } \\
\text { - Berkumpul } \\
\text { dengan keluarga } \\
\text { - Beristirahat }\end{array}$ & $\begin{array}{l}\cdot \text { Mencuci } \\
\cdot \text { Menjemur } \\
\cdot \text { Memasak } \\
\cdot \text { Membersihkan } \\
\text { rumah } \\
\text { - Merawat anak } \\
\text { - Berkumpul } \\
\text { dengan keluarga } \\
\text { - Aktivitas } \\
\text { dengan } \\
\text { komunitas } \\
\text { tertentu } \\
\text { - Arisan } \\
\text { - Beristirahat }\end{array}$ & $\begin{array}{l}\cdot \text { - Menonton TV } \\
\text { - Bermain } \\
\text { dengan } \\
\text { tetangga } \\
\text { - Berkumpul } \\
\text { dengan } \\
\text { keluarga } \\
\text { - Beristirahat }\end{array}$ \\
\hline
\end{tabular}

untuk menentukan akuator mana yang sesuai. Sehingga bangunan dapat benar-benar adaptif sesuai dengan kebutuhan.

\section{Actuation}

Adaptasi pada bangunan tergantung pada berbagai aktuator untuk menjalankan efek yang diharapkan. Aktuator melingkupi pencahayaan, ventilasi, material, dan hubungan komunikasi, untuk menampilkan media yang berbeda jenis. Aktuator didorong oleh sistem dan pengolahan teknologi. Aktuator bertanggung jawab untuk menciptakan efek yang diinginkan dalam Arsitektur Adaptif.

\section{HASIL DAN EKSPLORASI}

Perancangan rumah susun menerapkan prinsip-prinsip ekologi dalam buku Ecological Design [3]. Prinsip-prinsipnya diterapkan sebagai konsep dari rumah susun. Adapun beberapa konsep dari rumah susun diantaranya adalah:

\section{A. Konsep dijabarkan dari prinsip 'Solutions Grow from} Place'

Konsep ini diaplikasikan pada penentuan orientasi bangunan. Penentuan orientasi bangunan yang tepat akan membuat hunian nyaman dan mampu memaksimalkan potensi alam yang ada. Orientasi bangunan barat-timur dapat memaksimalkan potensi alam berupa pergerakan cahaya matahari dan angin. (Gambar 4)

\section{B. Konsep dijabarkan dari prinsip 'Ecological Accounting Informs Design'}

Keputusan desain yang diambil oleh perancang harus dapat meminimalisir dampak negatif pada lingkungan. Aplikasi dari konsep ini adalah penggunaan photovoltaic dan bak 
penampung air hujan (rain harvesting). Penggunaan photovoltaic diharapkan untuk mengurangi penggunaan energi yang berasal dari fosil. Penggunaan bak penampung air hujan (rain harvesting) dimaksudkan untuk mengurangi penggunaan air bersih.

\section{Konsep dijabarkan dari prinsip 'Design with Nature'}

Pengaplikasian dari prinsip ekologi ini terdapat pada bentuk bangunan. Bangunan dengan patio ditengahnya dan pelubangan pada sisi barat-timur dapat memasukkan potensi alam berupa cahaya matahari dan angin. Pemanfaatan potensi alam berguna untuk mengurangi penggunaan energi. (Gambar 5)

\section{Konsep 'Adaptable'}

Konsep ruang yang digunakan adaptable, agar penghuni dapat mengubah sesuai dengan kebutuhan mereka. Hal tersebut juga sebagai pengaplikasian prinsip ekologi 'everyone is designer'.

Desain adaptif lebih menitikberatkan pada konteks dan waktu, dibandingkan sekedar bentuk dan fungsi. Desain adaptif memiliki kemampuan menyesuaikan diri sesuai dengan kondisi yang baru. Salah satu karakteristik desain adaptif adalah open plan. Open plan adalah desain ruang mensimbolisasikan 'universal floor plan' dimana penghuni dapat menyusun atau membagi ruang sesuai dengan kebutuhan. (Gambar 6, 7, dan 8)

\section{E. Konsep dijabarkan dari prinsip Make Nature Visible}

Aplikasi dari konsep make nature visible terwujud pada selubung dan penataan massa.

\section{1) Selubung}

Aplikasi dari konsep ini adalah penggunaan material yang menyerupai karakter alam, yaitu kalsiplank tekstur kayu. Selain itu, penggunaan elemen vegetasi di selubung bangunan berguna untuk mengurangi radiasi matahari. (Gambar 9)

\section{2) Penataan Massa}

Salah satu penyebab kekumuhan adalah kurangnya lahan terbuka hijau. Oleh karena itu, aplikasi konsep ini pada penataan massa adalah pengaturan orientasi massa yang menuju pusat tapak. Hal tersebut dikarenakan pusat tapak merupakan sebuah ruang terbuka hijau. (Gambar 4 dan 9).

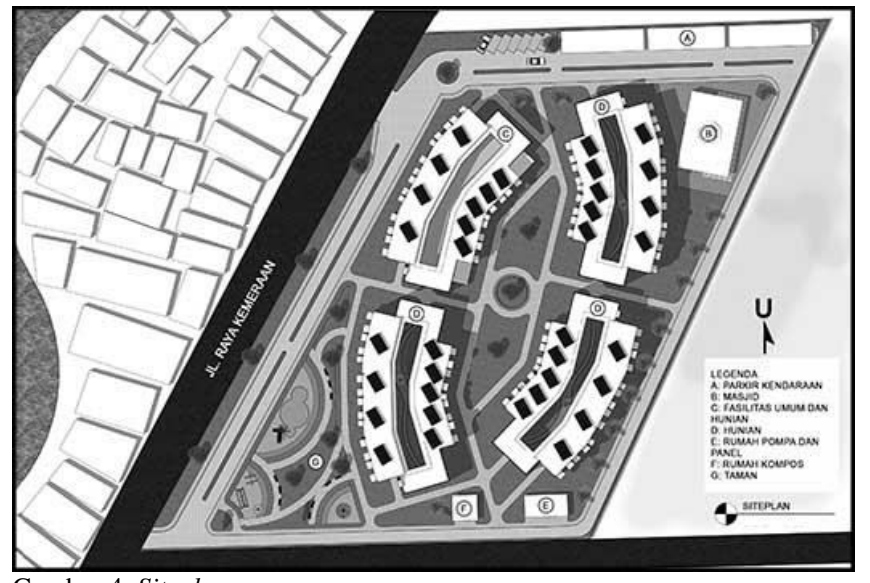

Gambar 4. Siteplan.

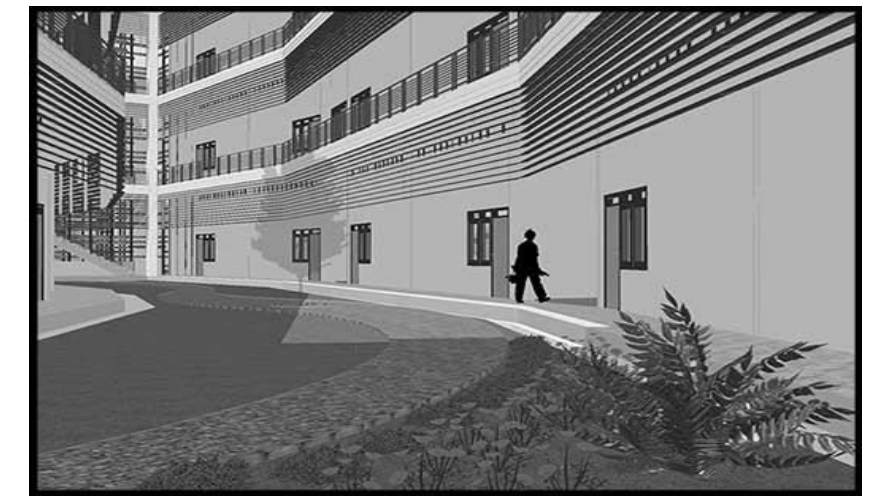

Gambar 5. Perspektif Eksterior (Patio).

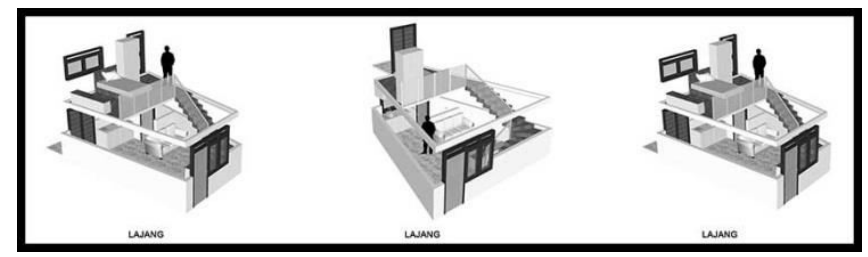

Gambar 6. Skenario Unit Penghuni Lajang (Adaptable).

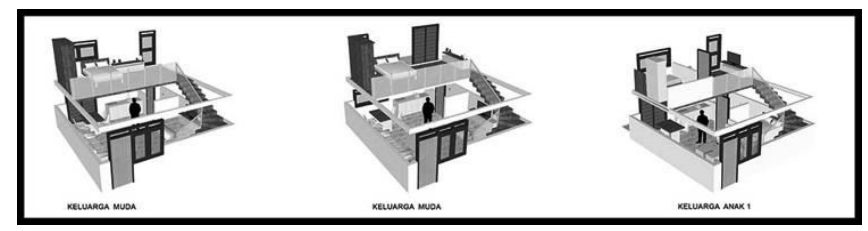

Gambar 7. Skenario Pertumbuhan Unit (Adaptable).

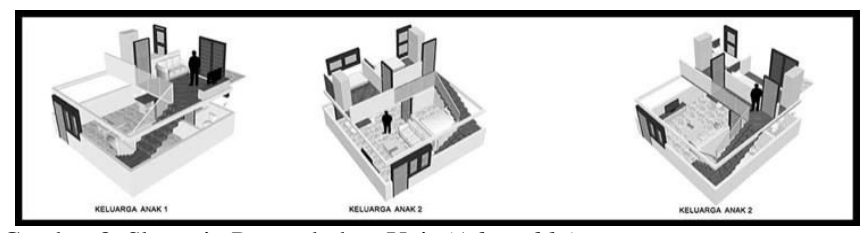

Gambar 8. Skenario Pertumbuhan Unit (Adaptable).

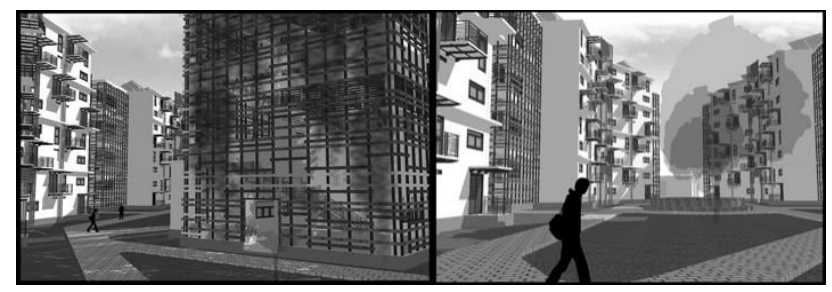

Gambar 9. Perspektif Eksterior (Selubung Bangunan dan Pusat Massa).

\section{KESIMPULAN}

Kekumuhan pada hunian pekerja pabrik dapat diminimalisir dengan desain adaptable dan ekologi. Desain adaptable dapat mengakomodasi adanya perubahan atau penambahan ruang sesuai dengan kebutuhan penghuninya. Hal tersebut dimaksudkan agar hunian mereka tidak terlihat berantakan

Pendekatan ekologi diterapkan agar bangunan tidak banyak memberikan dampak negatif pada lingkungan sekitar. Selain itu, pendekatan ini diharapkan akan membantu mengurangi pembiayaan dan penggunaan energi yang berasal dari fosil. 


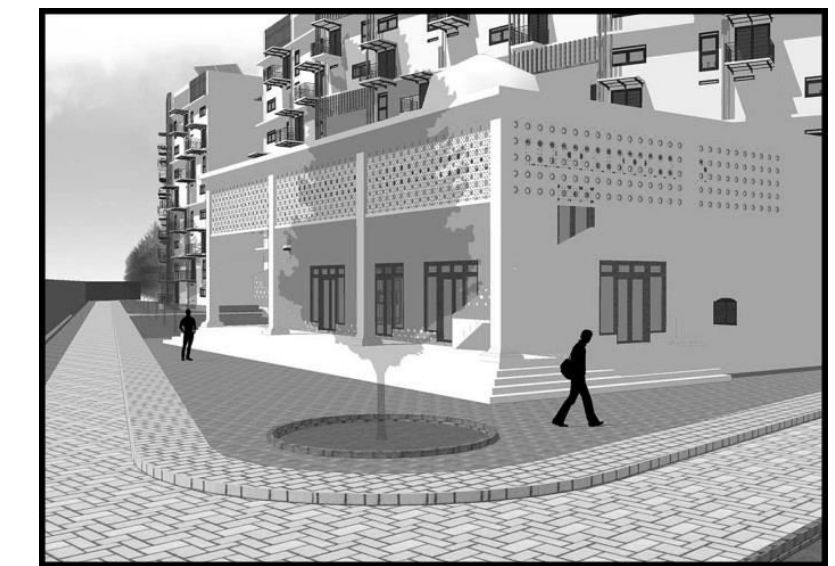

Gambar 10. Perspektif Eksterior (Masjid).

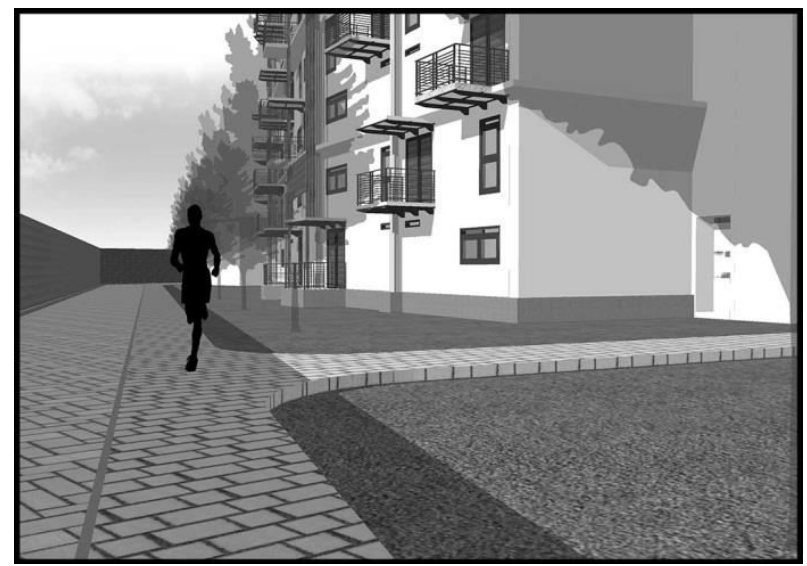

Gambar 11. Perspektif Eksterior (Jogging Track).

\section{DAFTAR PUSTAKA}

[1] A. Hafidian, "Arahan Penyediaan Fasilitas Pelayanan Kota di Daerah Urban Sprawl Surabaya," Surabaya, 2012.

[2] H. Schnädelbach, "Adaptive Architecture-A Conceptual Framework,"

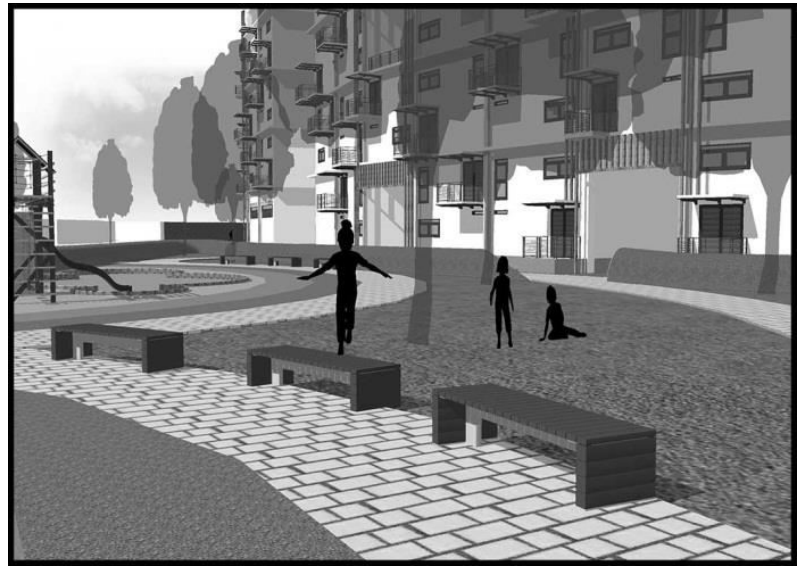

Gambar 12. Perspektif Eksterior (Taman).

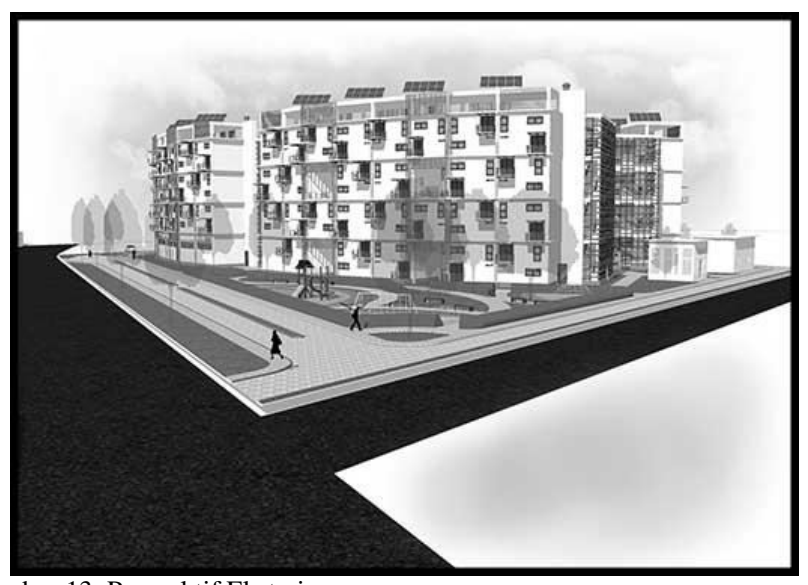

Gambar 13. Perspektif Eksterior.

2010.

[Online].

Available:

https://www.researchgate.net/publication/235218510.

[3] S. Van Der Ryn and S. Cowan, Ecological Design. Washington DC: Island Press, 1996. 